\title{
A study on eclampsia and its maternal and perinatal outcome
}

\author{
Devika J. Kamat*, Guruprasad Pednecar
}

Department of Obstetrics and Gynecology, Goa Medical College, Bambolim, Goa, India

Received: 28 September 2019

Accepted: 31 October 2019

\section{*Correspondence:}

Dr. Devika J. Kamat,

E-mail: devika.kamat@gmail.com

Copyright: (C) the author(s), publisher and licensee Medip Academy. This is an open-access article distributed under the terms of the Creative Commons Attribution Non-Commercial License, which permits unrestricted non-commercial use, distribution, and reproduction in any medium, provided the original work is properly cited.

\begin{abstract}
Background: Eclampsia is one of the major causes of maternal and perinatal mortality in India. Here authors present a prospective study which was conducted in a tertiary health centre to study the cases of eclampsia, the mode of presentation and the maternal and perinatal outcomes.

Methods: A total 95 women were diagnosed as eclampsia during the period of 2 years. Various parameters and their effects on maternal and perinatal morbidity and mortality were studied. Maternal outcomes were assessed based on parameters like antenatal care received, mode of delivery, complications associated with eclampsia. Perinatal outcomes were noted depending upon the period of gestation, NICU admission, stillbirths and neonatal deaths.

Results: Authors found the incidence of eclampsia to be $0.9 \% .52 .7 \%$ women had irregular antenatal follow up at any nearby health centre. A total $76.8 \%$ women had antepartum eclampsia. $56.8 \%$ delivered by caesarean section while $7.4 \%$ required operative vaginal delivery. $61.1 \%$ women delivered within 10 hours of onset of convulsion. Authors had 02 deaths in the study group, one due to ARDS with DIC and the other attributed to pulmonary oedema. There were $51.6 \%$ preterm deliveries. 21 neonates required NICU admission with 5 neonatal deaths and 11 stillbirths.

Conclusions: Due to inadequate antenatal care, most of the cases of pre-eclampsia go unnoticed increasing the referrals to tertiary care centre for intensive care. Thus, it is necessary to emphasise on timely interventions and availability of blood bank, ICU and NICU facilities at the closest referral centre for better maternal and perinatal outcome.
\end{abstract}

Keywords: Eclampsia, Maternal and perinatal mortality

\section{INTRODUCTION}

The modern era of obstetrics, holds prospects of not merely longer life, but superior quality of life, with less disability and disease. Maternal mortality is still a worrisome entity in the developing countries. Eclampsia is defined as seizures of grand mal type which cannot be attributed to any cause other than preeclampsia. ${ }^{1}$

Preeclampsia and eclampsia are associated with nearly one-tenth of maternal deaths in Asia and Africa and onequarter of maternal deaths in Latin America. ${ }^{2}$

It is worthwhile to periodically review eclampsia that leads to complications in about $01-100$ out of 1700 deliveries. ${ }^{3}$ Most of the eclamptic patients are brought to the hospital after a seizure episode at home in the antenatal or postnatal period which requires emergency intensive care. This adds to the morbidity associated with the disease due to delay in the initial emergency care that the patient needs to avoid complications.

Magnesium sulphate is the most preferred anticonvulsant and has been very effective in reducing maternal and perinatal mortality and morbidity. With low fit recurrence and quick recovery, the fetal salvage has also improved substantially.

With greater emphasis on antenatal care and creating awareness about high risk pregnancies in the general 
population, major burden of the disease can be reduced. The current study is based on assessing cases of eclampsia and their presentation with the maternal and perinatal outcomes in the institute.

\section{METHODS}

The prospective study was conducted over a period of 02 years in Goa medical college from June 2013 to June 2015 after prior approval by ethical committee. During this period there were 10524 deliveries in our hospital, of which 95 patients were diagnosed as cases of eclampsia.

\section{Inclusion criteria}

- Women who presented with eclampsia or developed the same during the hospital stay.

\section{Exclusion criteria}

- Cases of epilepsy, cerebral malaria, meningitis.

Data was obtained with respect to the booking status and antenatal follow up of each patient from the records provided. At the time of presentation, authors assessed the age, parity and gestational age. Authors examined the general status, BP and proteinuria using dipstick method. The onset of first convulsion, number of convulsions and time of administration of magnesium sulphate were also noted.

Laboratory evaluation was done including complete blood count, renal and liver function tests, coagulation profile, urine analysis, serum electrolyte status. Fundoscopic examination was also done.

Patient's vitals were monitored continuously in the eclampsia room of the department of obstetrics and gynaecology. Strict hourly assessment of urine output, deep tendon reflex and respiratory rate was done during the magnesium sulphate therapy to watch for any signs of magnesium toxicity. Mode of delivery was also noted keeping in mind the convulsion to delivery time. The parameters were then correlated with the maternal and perinatal outcomes respectively.

\section{Statistical analysis}

Data was statistically analysed using SPSS version 22.0 and categorical analysis done using Chi square test with $\mathrm{p}$ value $<0.05$ considered statistically significant.

\section{RESULTS}

During the present study the incidence of eclampsia was found to be $0.9 \%$. Age group of the study population ranged between 18-39 years with an average age of 23.74 years. $57.9 \%(55 / 95)$ were primigravidae. Out of all the cases of eclampsia only $4.2 \%$ (04/95) were booked cases in our hospital (Table 1).
Table 1: Booked cases at Goa Medical College during antenatal period.

\begin{tabular}{|lll|}
\hline Booked & No. of cases & Percentage $(\%)$ \\
\hline Yes & 04 & 4.2 \\
\hline No & 91 & 95.8 \\
\hline Total & $\mathbf{9 5}$ & $\mathbf{1 0 0}$ \\
\hline
\end{tabular}

Table 2: Total number of convulsions.

\begin{tabular}{|lll|}
\hline No. of convulsions & No. of cases & Percentage (\%) \\
\hline $01-02$ & 63 & 66.3 \\
\hline $03-04$ & 29 & 30.5 \\
\hline $05-06$ & 02 & 2.1 \\
\hline Status eclampticus & 01 & 1.1 \\
\hline Total & $\mathbf{9 5}$ & $\mathbf{1 0 0}$ \\
\hline
\end{tabular}

Of the 95 cases authors studied, 52.7\% (50/95) did not receive regular antenatal care at any health centre. Out of the referred cases, $16.4 \%(15 / 91)$ cases did not receive $\mathrm{MgSO}_{4}$ before referral. 76.8\% (73/95) cases developed eclampsia antepartum, $6.3 \%(6 / 95)$ intrapartum whereas $16.9 \%$ (16/95) developed postpartum eclampsia. Amongst antenatal cases (79/95), 83.4\% (66/79) developed eclampsia between 32-40 weeks gestation while $6.4 \%(5 / 79)$ patients developed eclampsia even before 28 weeks gestation. 66.3\% (63/95) had 1-2 convulsions, $30.5 \%$ (29/95) had 3-4, 2.1\% (2/95) had 5-6 convulsions. One patient developed status eclampticus and required ICU admission (Table 2).

Table 3: Convulsion to delivery interval.

\begin{tabular}{|lll|}
\hline $\begin{array}{l}\text { Convulsion to delivery } \\
\text { interval (in hours) }\end{array}$ & $\begin{array}{l}\text { No. of } \\
\text { cases }\end{array}$ & $\begin{array}{l}\text { Percentage } \\
(\%)\end{array}$ \\
\hline Less than 10 & 58 & 73.4 \\
\hline $11-20$ & 18 & 22.8 \\
\hline $21-24$ & 03 & 3.8 \\
\hline Total & $\mathbf{7 9}$ & $\mathbf{1 0 0}$ \\
\hline
\end{tabular}

Convulsion to delivery interval was found to be $<10$ hours in $73.4 \%(58 / 79)$ patients, $22.8 \%(18 / 79)$ delivered in $10-20$ hours whereas $3.8 \%(03 / 79)$ delivered in $21-24$ hours of convulsion (Table 3 ).

Among 32.9\% (26/79) delivered vaginally and $7.6 \%$ $(06 / 79)$ required instrumentation with vacuum or forceps application at the time of delivery. 62\% (49/79) delivered by lower segment caesarean section.

Maternal outcome: 32 out of 95 patients developed complications during the course of period. Most common complication associated with eclampsia that authors observed was hemodynamic instability (HELLP and DIC). Authors had 12 ICU admissions and 02 fatal cases with case fatality rate of $2.1 \%$. These patients died due to DIC with ARDS and pulmonary oedema (Table 4). 
It was found that maternal morbidity and mortality was significantly increased with the increase in number of convulsion $(p$ value $=0.045)$. It was also observed that antenatal eclampsia was associated with increased maternal morbidity and mortality than other types of eclampsia ( $\mathrm{p}$ value $=0.003$ ). Maternal morbidity was significantly increased with increased convulsion to delivery interval $(\mathrm{p}$ value $=0.04)$.

Table 4: Maternal outcome.

\begin{tabular}{|lllll|}
\hline Complications & No. of cases & ICU admissions & Death & Discharged \\
\hline HELLP & 05 & 01 & 00 & 05 \\
\hline DIC & 03 & 03 & 00 & 03 \\
\hline DIC with ARDS & 01 & 01 & 01 & 00 \\
\hline Abruptio placentae & 05 & 00 & 00 & 05 \\
\hline PRESS & 03 & 00 & 00 & 03 \\
\hline PPH & 03 & 00 & 00 & 03 \\
\hline ARF & 01 & 01 & 00 & 01 \\
\hline Abruptio placentae with ARF with PRESS & 01 & 01 & 00 & 01 \\
\hline HELLP with PRESS & 01 & 01 & 00 & 01 \\
\hline Pulmonary oedema & 01 & 01 & 01 & 00 \\
\hline ARDS & 01 & 00 & 00 & 01 \\
\hline Peripartum cardiomyopathy & 01 & 01 & 00 & 01 \\
\hline Status eclampticus & 01 & 01 & 00 & 01 \\
\hline Aspiration pneumonia & 01 & 00 & 00 & 01 \\
\hline Papilledema with glottic oedema & 01 & 01 & 00 & 01 \\
\hline No complications & 66 & 00 & 00 & 66 \\
\hline Total & $\mathbf{9 5}$ & $\mathbf{1 2}$ & $\mathbf{0 2}$ & $\mathbf{9 3}$ \\
\hline
\end{tabular}

Perinatal outcome: In our study there were 51.6\% (49/95) preterm deliveries. Out of 46 term deliveries 54\% (25/46) were less than $2500 \mathrm{~g}$ whereas $46 \%$ (21/46) were more than $2500 \mathrm{~g}$. Authors had $16.8 \%$ (16/95) perinatal deaths including 11 stillbirths and 05 neonatal deaths (Table 5).

Table 5: Perinatal outcome.

\begin{tabular}{|lcc|}
\hline Perinatal outcome & $\begin{array}{c}\text { No. of } \\
\text { cases }\end{array}$ & $\begin{array}{l}\text { Percentage } \\
(\%)\end{array}$ \\
\hline Perinatal death & 16 & 16.8 \\
\hline Neonates discharged from NICU & 21 & 22.1 \\
\hline No admission & 58 & 61.1 \\
\hline Total & $\mathbf{9 5}$ & $\mathbf{1 0 0}$ \\
\hline
\end{tabular}

It was also observed that the increase in the number of convulsions significantly increased perinatal morbidity and mortality $(\mathrm{p}$ value $=0.003$ ). The perinatal morbidity and mortality significantly increased with the increase in the convulsion to delivery interval ( $\mathrm{p}$ value $=0.043$ )

\section{DISCUSSION}

Eclampsia is the commonest cause of convulsion in pregnancy. Like other developing countries, eclampsia is still a major cause of obstetric problems in India. Incidence of eclampsia varies from $1: 100$ to $1: 1700$ in developing countries. ${ }^{4}$
Maternal complications due to eclampsia are serious and include disseminated intravascular coagulopathy, renal insufficiency, raised intracranial tension, pulmonary oedema and cardiorespiratory arrest.

Eclampsia is also associated with increased perinatal mortality. The causes of perinatal mortality include prematurity, low birth weight, sepsis, perinatal asphyxia, placental infarcts, abruptio placentae, intrauterine growth restriction. The present study was carried out to study the cases of eclampsia and the various factors that affect the maternal and perinatal morbidity and mortality.

The incidence of eclampsia in our hospital is $0.9 \%$. This is comparable to the incidence of eclampsia in studies done at other tertiary care centres in our country i.e. Sunitha et al (1\%), Prabhakar et al (1.09\%), Mor et al $(1.08 \%) .^{5-7}$ However the incidence is considerably higher than that of the developed countries (Finland $0.024 \%$, UK $0.072 \%$, USA $0.028 \%) .{ }^{8-10}$

In our study authors found that $73.7 \%$ women were primigravidas which was comparable to other studies conducted by Tukur et al and Akhtar et al who found that $78 \%$ and $72.5 \%$ were primigravidas in their respective studies. ${ }^{11,12}$

In the study conducted by Shaheen et al and Sarma et al, $63 \%$ and $65 \%$ of women respectively were in the age 
group of less than 25 years. ${ }^{13,14}$ These results were consistent with our study where authors found $64.1 \%$ women in the age group of less than 25 years. This could probably be because of larger number of primigravidas in this age group, which is a high-risk factor for preeclampsia and eclampsia. Also, the customs in our population support early marriage and most of the women complete their families by the age of 30 . Hence most of the patients admitted in our hospital belonged to a younger age group.

In the study by Edgar et al and Sunitha et al it was found that $4 \%$ and $5 \%$ of women respectively were booked patients who had received antenatal care but developed eclampsia which was comparable to our study with $4.2 \%$ of booked patients that developed eclampsia. ${ }^{5,15}$

In recent studies by Prabhakar et al and Sarma et al, eclampsia was seen prior to completion of 37 weeks of gestation in $49.9 \%$ and $55 \%$ of patients respectively. ${ }^{6,14}$ The results of our study were comparable to the above results i.e. eclampsia was seen in $55.7 \%$ patients before 37 weeks of gestation.

In the study by Prabhakar et al and Vijayashree $\mathrm{M}$ et al, it was observed that antenatal eclampsia was found in $77.4 \%$ and $71.2 \%$ of the cases respectively. ${ }^{6,16}$ Our study also showed that $76.8 \%$ women had antepartum eclampsia.

In the study conducted by Choudhary $\mathrm{P}$ and Aisha et al, vaginal delivery was seen in $45 \%$ and $46 \%$ of the cases respectively, similar to our study with $40.6 \%$ of the cases that delivered vaginally. ${ }^{17,18}$

Our case fatality rates of $2.1 \%$ in the study was comparable to that of studies conducted by Douglas et al and Asiciolglu et al i.e. $1.8 \%$ each. ${ }^{19,20}$

Increase in the number of convulsions increased the risk of the maternal morbidity and mortality significantly in our study $(p$ value $=0.045)$. Similar observation was made by Sunitha et al and Vijayashree et al in their study. 5,16

Authors observed that longer convulsion to delivery interval significantly affected the maternal outcome ( $p$ value $=0.045)$ There was a significant increase in maternal morbidity with increase in convulsion to delivery time, as seen in studies conducted by Anuja et al and Khan et al. ${ }^{21,22}$

Authors found that $80 \%$ of eclamptic patients had babies with birth weight less than $2500 \mathrm{~g}$. Similar results were observed in other studies conducted by Dhananjaya et al and Rajesri et al, with $89 \%$ and $78 \%$ of babies respectively with birth weight less than $2500 \mathrm{~g}$. ${ }^{23,24}$ This was probably because of higher number of preterm deliveries (spontaneous and induced) as well as intrauterine growth restriction which is a known complication of preeclampsia.

In the study conducted by Choudhary $\mathrm{P}$ and Edgar et al, ${ }^{15,17}$ the stillbirth rate was found to be $14 \%$ and $12.2 \%$ respectively which was comparable to our study with a stillbirth rate of $11.5 \%$. Also, the neonatal death rate of $5.3 \%$ in our study was comparable to that of studies by Choudhary $\mathrm{P}$ and Anuja et al i.e. $6 \%$ and 5.4\% respectively. ${ }^{17,21}$

In the present study the perinatal mortality was $20 \%$ when the convulsion to delivery interval was more than 12 hours, whereas in the studies by Anuja et al and Rajesri et al, perinatal mortality was $68.2 \%$ and $40 \%$ respectively. ${ }^{21,24}$ This could be explained by the fact that in our study there were comparatively fewer patients with convulsion to delivery interval of more than 12 hours in the study population due to more liberal use of caesarean sections and better NICU facilities available..

\section{CONCLUSION}

Eclampsia is an ongoing challenge for the whole medical community, the root of which lies in the soil of illiteracy, poverty and poorly implemented health care system. Hence regular antenatal follow up with early detection of hypertensive changes have to be reinforced to every mother during their routine visits to health care centres.

With provision of proper transport and medical assistance at first referral level, as well as strengthened intensive care at tertiary level authors can expect a decrease maternal and perinatal mortality in eclampsia significantly. Such interventions will have positive impact on maternal and child care and decrease incidence of eclampsia.

\section{ACKNOWLEDGMENTS}

Authors would like to express their gratitude towards the department of obstetrics, paediatrics and anesthesiology for their support during the study.

Funding: No funding sources

Conflict of interest: None declared

Ethical approval: The study was approved by the Institutional Ethics Committee

\section{REFERENCES}

1. Gifford RW, August PA, Cuuningham G, Green LA, Lindheimer M, McNellis D, et al. Working group of National High Blood Pressure Education Programme. NIH Publication No. 00-3029 revised; 2000:3-5.

2. World Health Organisation. WHO recommendations for prevention and treatment of pre-eclampsia and eclampsia 2011. Available at: 
http://whqlibdoc.who.int/publications/2011/9789241

548335_eng.pdf. Accessed on $8^{\text {th }}$ October 2019.

3. Patil MM. Role of neuroimaging in patients with atypical eclampsia. J Obstet Gynaecol India. 2012;62(5):526-30.

4. World Health Organisation. International Collaborative study of hypertensive disorders of pregnancy, geographic variation in the incidence of hypertension in pregnancy. Am J Obstet Gynaecol. 1988;158(1):80-3.

5. Sunitha TH, Dessai R. Eclampsia in a teaching hospital: incidence, clinical profile and response to magnesium sulphate by Zuspan's regimen. IOSR-J Dent Med Sci. 2013;4(2):1-5.

6. Prabhakar G, Shinde MA, Jadhav CA. Clinical study of eclampsia at Dr. V. M. Government medical college Solapur, IOSR-JDMS. 2014;13(7):10-6.

7. Mor S, Daya S, Reetu H. Eclampsia: maternal and perinatal outcome in a tertiary care centre. In J Repro Contra Obstet Gynaecol. 2015;4(3):653-7.

8. Eckholm E, Salmi MM, Erkkola R. Eclampsia in Finland in 1990-1994. Acta obstetricia et gynaecologia Scandnavica. 1999;78(10):877-82.

9. Leitch R, Walker JJ. The changing pattern of eclampsia over a 60 year period. Br J Obstet Gynaecol. 1997;104:917-22.

10. Mahmoudi N, Graves SW, Solomon CG, Repke John T, Seely EW. Eclampsia: 13 year experiences at a United States Tertiary care center. J Women's Health Gender-Based Med. 1999;8:495-500.

11. Tukur J, Umar BA, Rabiu A. Pattern of eclampsia in a tertiary health facility situated in a semi rural town in Northern Nigeria. Anna Af Med. 2007;6:164-7.

12. Akhtar R, Ferdous A, Syeda B. Maternal and fetal outcome of eclamptic patients in a tertiary hospital. Bangladesh J Obstet Gynaecol. 2011;26(2):77-80.

13. Shaheen B, Hassan L, Obaid M. Eclampsia: a major cause of maternal and perinatal mortality; a prospective analysis at a tertiary care hospital of Peshawar. J Peshawar Med Asso. 2003;53(8):34650 .

14. Sarma HK, Talukdar B. Eclampsia: a clinical prospective study in a referral hospital. J Obstet Gynaecol Barpeta. 2014;1(1):57-61t.
15. Edgar MN, Albert K, Richard R, Beatrice I, Anthony NM. Maternal and perinatal outcome among eclamptic patients admitted in Bugando Medical College, Mwanza, Tanzania. Af J Repro Health. 2012;16(1):35-41.

16. Vijayashree M, Murali GV. A clinical study of perinatal and maternal complications in eclampsia in a tertiary level referral centre - A near miss obstetric catastrophe. Int J Adv Multidi Res. 2015;2(4):80-5.

17. Choudhary P. Eclampsia: a hospital based retrospective study. Kathmandu Univ Med J. 2003;1(4):237-41.

18. Abdullah A, Shaikh AA, Jamro B. Maternal and perinatal outcome associated with eclampsia in a teaching hospital, Sukkur. Rawal Med J. 2010;35(1):23-6.

19. Douglas KA, Redman CW. Eclampsia in United Kingdom. Br Med J. 1994;309(6966):1395-400.

20. Asicioglu O, Gungorduk K, Yildirim G, Aslan H, Gunay T. Maternal and perinatal outcomes of eclampsia with or without HELLP syndrome in a teaching hospital in western Turkey. J Obstet Gynecol. 2014;34:326-31.

21. Anuja B, Sayali K, Sunita G, Anjali K, Sulabha J, Savita S. Eclampsia: maternal and fetal outcome. J South Asian Federat Obstet Gynecol. 2013;5(1):1921.

22. Khan A, Arindam G, Banerjee PK, Tapan KM. Profile and outcome of eclampsia in a rural tertiary hospital. Int $\mathbf{J}$ Recent Trends Sci Tech. 2014;10(3):526-9.

23. Dhanajaya BS, Dayananda G, Sendilkumaran D, Murthy N. A study of factors affecting perinatal mortality in eclampsia. J Pharm Bioallied Sci. 2009;22(2):2-5.

24. Yaliwal RG, Jaju PB, Vanishree M. Eclampsia and perinatal outcome: a retrospective study in a teaching hospital. J Clin Diag Res. 2011;5(5):1056-59.

Cite this article as: Kamat DJ, Pednecar G. A study on eclampsia and its maternal and perinatal outcome. Int J Reprod Contracept Obstet Gynecol 2019;8:4990-4. 